\title{
Economics
}

The Open-Access, Open-Assessment E-Journal

Vol. 12, 2018-56 | September 05, 2018 | http://dx.doi.org/10.5018/economics-ejournal.ja.2018-56

\section{Bobos in paradise: urban politics and the new economy}

\section{Gilles Saint-Paul}

\begin{abstract}
This paper provides some elements to explain the observed takeover in some urban areas of a new kind of elite associated with new economy jobs, also known as "bourgeois bohème" (bobos). This takeover has been associated with greater investment in urban amenities and "clean" means of transport, with adverse effects on commuting time. The model allows us to explain those developments by productivity growth in the new economy, and by the differences in production processes between the new and old economies. The consequences of bobo takeover for house prices and employment of unskilled service workers are also discussed. A bunkerized equilibrium in which skilled workers in the old economy no longer reside in the city and have been replaced by service workers is studied. In such an equilibrium urban amenities are at their maximum and commuting flows have been eliminated. For some parameter values, bobos are better-off under bunkerization, in which case they may gain by favoring it with a "diversity" subsidy for unskilled workers to reside in the city.
\end{abstract}

JEL $\quad$ H7 R3 R4 R5

Keywords New economy; urban amenities; bobos; residential choice; local public goods; urban voting models; bunkerization

\section{Authors}

Gilles Saint-Paul, Paris School of Economics (ENS-PSL), France; New York University Abu Dhabi, United Arab Emirates, gstpaulmail@gmail.com

Citation Gilles Saint-Paul (2018). Bobos in paradise: urban politics and the new economy. Economics: The Open-Access, Open-Assessment E-Journal, 12 (2018-56): 1-36. http://dx.doi.org/10.5018/economics-ejournal.ja.2018-56

This paper has benefitted from comments by seminar participants at the London School of Economics, CEMFI Madrid, the Bank of Spain, the University of Zürich, two anonymous referees, and the NBER Summer Institute EFGImeeting on income distribution. I am grateful to Cyril Couaillier for excellent research assistance, as well as Paris Sciences Lettres and OSElunder grant ANR-10-LABX-93 for research support. 


\section{Introduction}

The term "bobo" stands for "Bourgeois Bohème" and was coined by David Brooks (2000) in a famous book about the rise of a new knowledge elite. This new kind of bourgeoisie is generally considered as prevalent in globalized capital cities, and its lifestyle and political attitude stand in contrast to that of the traditional bourgeoisie. Furthermore, the bobos are generally viewed as a politically powerful group. They have been instrumental in bringing about left-wing governments in municipalities such as Berlin, Paris or San Francisco, despite the relatively high economic status of this social class.

Economically, the bobos are "symbol manipulators": teachers, intellectuals, professionals, journalists, advertisers, architects, and "connected" workers of the new economy.

In terms of consumption attitudes, the bobos promote a relaxed lifestyle where conspicuous consumption is banned. They seek human scale habitat and a "village" atmosphere, while generally living in large metropolitan areas (an early example of such conceptions is Jacobs (1961)). They insist on environmental quality and promote public transportation or bicycles. They value "arts", in particular in their most modern forms: contemporary arts, rock concerts, and so forth.

Politically, the bobos are viewed as generally supportive of environmentalist and/or socialist parties. Their takeover of major cities has taken place in the context of sharply increasing house prices from the mid-1990s to the onset of the financial crisis, and led to policies that recognizably differ from the ones implemented both by the right and by the traditional left. These policies can be summarized as follows ${ }^{1}$ :

- Greater investment in collective urban amenities and socialized recreational events.

- Reduced urban space for the automobile, generally coupled with a reduction in parking space, higher taxes and more stringent regulations and constraints for personal vehicles. More investment in public transportation and in dedicated areas for bicycles and other "clean" means of transportation. Public provision of cheap bike and electrical car rental, and dedication of public space to those devices.

- Promotion of "social mixity" and "diversity", by means of transfer policies and/or subsidized housing that maintain a critical mass of lower class dwellers in the city center, while intermediate classes are eliminated and relocate themselves in the outer periphery ${ }^{2}$.

1 See Brooks (2000), Chapter 7.

2 See Guilluy (2010), for a discussion of those relocation flows in the French case. See also Clerval and Fleury, 2009, for a discussion of the Paris case. 
This paper provides some elements for understanding these developments from a "pure economic perspective". By this I mean that I will attempt to explain them as a consequence of technological developments, instead of just assuming that bobos are a new kind of individuals with their own preferences. The paper focuses on the relative roles of, and conflict of interest between two kinds of bourgeoisie: The skilled workers of the old economy (called cadres) versus the skilled workers of the new economy (bobos) ${ }^{3}$. The former work in activities that are more land intensive, while still preferring to live in a city centre. As a result they derive more utility from commuting and are less willing to raise commuting costs in order to improve urban amenities than the bobos. The paper shows that as the new economy grows faster than the old economy, the bobos overtake the cadres as the politically decisive group in the city. As a result, the level of urban amenities goes up and so do transportation costs. The consequences for house prices and the cost of services are also studied, as well as the implications for suburban unemployment of the lower classes. A notable result is that there may be multiple equilibria: For a range of productivity levels in the new economy, an equilibrium where cadres dominate in the city co-exists with an equilibrium where the bobos are the politically decisive class.

Finally, I also show that it may be profitable for the decisive bobo class to subsidize location of lower class unskilled workers in the city, in absence of any altruism toward them or intrinsic taste for a socially diverse makeup of the city. This is because such subsidies allow to force the economy to settle in a "bunkerized" equilibrium in which the service providers to city dwellers are located in the city, so that the price of services no longer goes up with the amenity level. As a result, ex-post there is no cost to raising the amenity level in the city, and the resulting political equilibrium involves the highest possible levels of amenities and transportation costs.

I then discuss data on the evolution of the top 50 French urban areas between 2007 and 2012, looking at variables such as house prices, tramway and bicycle provision, social housing, new economy employment, household service employment, and real estate prices. These data broadly support the model's predictions.

The model is an application of voting equilibrium theory under interjusdictional mobility, as was studied by Rose-Ackerman (1979), Westhoff (1977), Richter (1982), Epple et al. (1983, 1984), to the specific urban trends that have been oberved in the recent decades. Seegert (2011), for example, relates to the current paper in that he studies the optimal choice of amenities and

\footnotetext{
3 These two groups differ in income, in addition to occupation. As will be shown below, in equilibrium the bobos may be a majority in the city even though they earn less than the cadres, provided the gap is not too large. But the analysis equally applies to a situation where the bobos earn more than the cadres, regardless of the size of the gap. That is, the cadres alternatively may be interpreted as an intermediate class, as long as they work in the land intensive sector.
} 
land regulation by insiders in cities; the research question and model design are however entirely different ${ }^{4}$.

This paper is also related somewhat to the large sociological literature on gentrification pioneered by Glass $(1964)^{5}$. This literature, however, generally fails to identify conflicts of interest within the bourgeoisie, sticking instead with the traditional marxist scheme of class conflict. Instead, I focus on the conflict of interests between two categories of skilled workers that work in different types of occupation.

Another relatively unusual aspect of the model is its departure from the traditional assumption that all economic activity must take place in the Central Business District, as, say in, Leroy and Sonstelje's (1983) analysis of commuting gentrification. Here the existence of land-intensive economic activities located in the suburbs plays a key role in the analysis. In particular, greater amenities do not necessarily raise land prices, because commuting costs go up, which reduces the marginal willingness to pay for living in the city by cadres ${ }^{6}$. This is unlike the CBD-based literature on price-based estimation of the hedonic value of urban amenities (Rosen, 1979, Roback, 1982).

An illustration of the phenomena analyzed here in the case of Paris is the fate of the so-called "axes rouges". These policies were introduced by Paris mayors Jacques Chirac and Jean Tiberi and consisted in preventing parking along the side of a number of designated large arteries, in order to improve traffic. In contrast, the socialist Delanoe administration, which took over in 2001, had a deliberate policy of reallocating space away from automobile traffic and in favor of alternative means of transport as well as recreational activities ${ }^{7}$. Consequently, the axes rouges were abolished. It is generally considered that the gentrification process was already well under way under the Chirac and Tiberi administrations. The introduction of axes rouges should therefore be understood as catering to the Parisian upper-middle class voter of that time, and conversely their abolition

\footnotetext{
4 In his model, individuals are identical, amenities are site-specific (so that choosing amenities can only occur through the choice of which site to develop), and the key question is how efficient is the distribution of population depending on who chooses land regulation.

5 There are also a number of economic studies of gentrification, like Rossi-Hansberg et al. (2008), Guerrieri et al. (2010), who focus on the geographical spread of increases in land prices following income growth or investment in amenities. This kind of effects is also present in the current model, but the focus is on the politico-economic equilibrium, not on gentrification per se.

6 I am grateful to an anonymous referee for pointing this to me.

7 These policies culminate with the recent plan by Anne Hidalgo, new Paris mayor, to entirely eliminate the automobile from the capital in 2020. For a polemical assessment, see, Roger-Petit (2015).
} 
should be interpreted as a shift in the preferences of the median voter, as analyzed in this paper, not as public policies working toward gentrification. ${ }^{8}$

\section{The model}

In this section, I lay out the main assumptions of the model. This is a static partial equilibrium model of an area with two locations: city and periphery (The model can be slightly enriched through an overlapping generations structure, which is described in Appendix III. This delivers some additional results regarding the dynamics of house prices in the transition between equilibria). Unlike the traditional central business district models, economic activity is not constrained to take place in the city 9 .

\subsection{Workers and skills}

There are three categories of workers:

- Skilled workers specialized in the new economy, thereafter referred to as "Bobos". The total number of bobos is fixed and equal to $H_{1}$. Each of them is endowed with one unit of specialized skilled (type 1) labor.

- Skilled workers specialized in the old economy, that I will refer to as "Cadres"10. There are $\mathrm{H}_{2}$ of them, each endowed again with one unit of (type 2) skilled labor.

- Unskilled workers, called "workers", who are specialized in services. There are $L$ workers in the economy, each endowed with one unit of unskilled labor.

\subsection{Goods and production}

There are five goods:

- A generic consumption good which is imported, and whose price is normalized to one. This good will be used as the numéraire.

\footnotetext{
8 Clerval and Fleury (2009) document the evolution of the Delanoe administration's urban policies and the differences with the preceding administration. They also show that gentrification had occured prior to the taking over of the Socialist Party, although they also argue that Delanoe's policies reinforced the gentrification process, contrary to his claims.

9 For the analysis of polycentric cities, see Anas and Kim (1996), Anas et al. (1998) and Okamoto (2007).

${ }^{10}$ This French word loosely means "executive", but it is also associated with a conventional lifestyle with a substantial emphasis on consumer's society, as opposed to the more counter-cultural lifestyle of the bobos. The cadre lifestyle is described to some extent in Barthes (1957), and its somewhat more austere U.S. equivalent is discussed in Brooks (2000), in his analysis of the "Bourgeois" versus the "Bohemians".
} 
- Two exported goods, whose prices are also normalized to one, without loss of generality ${ }^{11}$.

- A new economy good, good 1, whose production only involves type 1 skills. The production function is

$$
y_{1}=a_{1} h_{1},
$$

where $y_{1}$ is output and $h_{1}$ the input of type- 1 skill.

- An old economy good, good 2, whose production uses both type 2 skills and land. The production function is

$$
y_{2}=\min \left(a_{2} h_{2}, x_{2} / b\right)
$$

where $x_{2}$ is the land input into good 2 and $h_{2}$ the type 2 skill input. The equilibrium wage of type 2 labor working in location $i$ is therefore equal to

$$
w_{2}=a_{2}\left(1-b R_{i}\right)
$$

where $R_{i}$ denotes the rental cost of housing in location $i .^{12}$

- Services, denoted by subscript $S$. These services only use labor. The production function is

$$
y_{S}=a_{S} l_{S}
$$

where $l_{S}$ is the input of labor. Furthermore, in order to supply a service, workers must be physically located in their customer's residential area.

- Housing: at any time, one unit of land can be converted into one unit of housing at no cost. Therefore, the production fonction for housing is $y_{H}=x_{H}$, where again $x_{H}$ denotes the land input into the production of housing, and $y_{H}$ the number of housing units thus obtained. For simplicity, I assume housing is owned by an outside population which neither votes nor consumes in the city or the periphery.

\footnotetext{
${ }^{11}$ These goods being traded, their prices are treated as exogenous as long as the city is small relative to the global market size for those goods. If $p_{1} \neq 1$, the analysis below is unchanged as long as $a_{1}$ is reinterpreted as $p_{1} a_{1}$ and similarly if $p_{2} \neq 1 a_{2}$ can be reinterpreted as $p_{2} a_{2}$ and $b$ as $b / p_{2}$.

12 While the assumption that land plays no role in the production of good 1 drastically simplifies the analysis, what really matters is that it is less intensive in land than good 2, and similarly for services.
} 


\subsection{Geography}

There are two areas

- The center (C), or "city", which has a fixed size in terms of land. An amount $X$ of this land is usable either for housing or as an input to good 2. I will assume that

$$
\max \left(H_{1}, H_{2}\right)<X<2 \min \left(H_{1}, H_{2}\right) .
$$

This assumption implies that the entire bobo or cadre population may fit in the city, and that if it is the case, the corresponding group will be a political majority. In addition to that, a fixed amount of additional land is allocated to public goods, that are divided between urban amenities and transportation infrastructures. As will be clear below, we do not actually need to specify that amount.

- The periphery (P), or "suburb", with an infinite supply of land. In the periphery, there is a fixed, exogenous level of amenities, which is normalized to zero. This allows us, for simplicity, to limit the political economy analysis to the city, which is the focus of the paper.

In the city, public decisions over amenities involve reallocating available space for public goods between amenities and transportation infrastructures. As a result, there is a trade-off between amenities and commuting costs ${ }^{13}$. I assume that this trade-off is summarized by a positive relationship between $\phi$, the level of transportation costs, and $\alpha$, the amenity level in the city:

$$
\phi=\phi(\alpha), \phi^{\prime}, \phi^{\prime \prime}>0, \phi^{\prime}(0)=0 .
$$

There exists a maximum possible level of amenities $\alpha_{C}$. The corresponding commuting cost is $\phi_{C}=\phi\left(\alpha_{C}\right)$.

Note that city size is fixed, which allows me to ignore the role of agglomeration and congestion externalities. To make city size endogenous, these externalities would have to be introduced, which would potentially deliver a richer set of predictions but substantially raise the model's complexity.

\footnotetext{
${ }^{13}$ A typical example is the reduction in car lanes to make way for other, more agreeable transportation means such as bicycles, that are beneficial to city residents but not to commuters. A more striking example is the decision by Ms. Hidalgo, mayor of Paris, to convert large portions of a motorway along the Seine river (called voies sur berges) into pure recreational areas.
} 


\subsection{Preferences}

All agents have the same utility function, given by

$$
U\left(c, c_{S}, \delta, \phi\right)=\ln c+\beta \ln c_{S}-\delta \phi+\gamma,
$$

where

- $c$ is the consumption of the generic consumption good,

- $c_{S}$ is consumption of services

- $\delta$ is a dummy equal to one if the person commutes and zero if not

- $\gamma$ if the amenity level, which is equal to $\alpha$ in the city and zero in the suburb.

Furthermore, each individual exactly consumes one unit of housing.

I assume that

$$
\phi^{\prime}\left(\alpha_{C}\right)>(1+\beta) / \beta
$$

which, as will be clear below, guarantees an interior equilibrium amenity level in regimes I and II.

Instead of working and consuming, people can instead live in autarky, in which case they get a reservation utility equal to $\bar{u}$. Also, I will limit the analysis to a regime where the constraint $u \geq \bar{u}$ is binding for workers only. Consequently, only a fraction of the total mass of workers $L$ will be employed, and the others will be "unemployed"14. An increase in $\bar{u}$ can also be interpreted as an increase in the generosity of welfare benefits.

\section{Consumption, production, and location}

The timing is as follows: first people decide on where to live and the housing market clears, then residents of the city vote over its amenity level. Finally, people produce (which may involve commuting) and consume and goods markets clear. Note that with this timing, the market price of housing is predetermined when people vote over amenities.

In this section and the following I describe how to solve for the equilibrium. I will solve the problem in three steps:

\footnotetext{
${ }^{14}$ The unemployed necessarily live in the periphery: they could not afford the housing cost in the city.
} 
1. The consumption and production decisions of all three social classes when old, as a function of their residential location.

2. The locational decisions of the young of the three classes, as a function of expected amenity levels and housing costs..

3. The voting decision of urban households on amenities, as a function of the sociological composition of the city.

The equilibrium concept prevailing here is essentially the same as in Epple et al. (1984): there is equilibrium in goods markets, each location is internally in a majority voting equilibrium, and no individual can gain by changing residence.

\subsection{Consumption and production decisions}

Let $y$ be an individual's income net of housing costs, and $p_{S}$ the price of services in his or her community, equal to $p$ in the periphery and to $p^{*}$ in the city. Clearly, from (2), $c=\frac{y}{1+\beta}$ and $c_{S}=\beta \frac{y}{(1+\beta) p_{S}}$. Consequently, indirect utility is equal to, up to a constant

$$
V\left(y, p_{S}, \delta, \gamma\right)=(1+\beta) \ln y-\beta \ln p_{S}-\delta \phi+\gamma
$$

Two worker types may potentially be commuters. Workers may commute to offer their service to consumers not located in their area. Cadres may commute to a production site in the other area, as land itself is not moveable.

Table 1 gives us the value of $y$ as a function of residential location and work location for the three social classes, where $R$ denotes the rental price of housing ${ }^{15}$. From this, we can compute the utility of each class, which is reported in Table 2.

\begin{tabular}{lll}
\hline \hline Class & Work in city & Work in suburb \\
\hline Workers in city & $p^{*} a_{S}-R$ & $p a_{S}-R$ \\
Workers in suburb & $p^{*} a_{S}$ & $p a_{S}$ \\
Bobos in city & $a_{1}-R$ & $a_{1}-R$ \\
Bobos in suburb & $a_{1}$ & $a_{1}$ \\
Cadres in city & $a_{2}(1-b R)-R$ & $a_{2}-R$ \\
Cadres in suburb & $a_{2}(1-b R)$ & $a_{2}$ \\
\hline \hline
\end{tabular}

Table 1: Income

\footnotetext{
$\overline{15}$ Note that this does not reflect commuting costs that are incurred as a disutility instead of an income loss.
} 


\begin{tabular}{ll}
\hline \hline Class & Work in city \\
\hline Workers in city & $(1+\beta) \ln \left(p^{*} a_{S}-R\right)-\beta \ln p^{*}+\alpha$ \\
Workers in suburb & $(1+\beta) \ln \left(p^{*} a_{S}\right)-\beta \ln p-\phi$ \\
Bobos in city & $(1+\beta) \ln \left(a_{1}-R\right)-\beta \ln p^{*}+\alpha$ \\
Bobos in suburb & $(1+\beta) \ln a_{1}-\beta \ln p-\phi$ \\
Cadres in city & $(1+\beta) \ln \left(a_{2}-R\left(1+a_{2} b\right)\right)-\beta \ln p^{*}+\alpha$ \\
Cadres in suburb & $(1+\beta) \ln \left(a_{2}(1-b R)\right)-\beta \ln p-\phi$ \\
\hline \hline Class & Work in suburb \\
\hline Workers in city & $(1+\beta) \ln \left(p a_{S}-R\right)-\beta \ln p^{*}+\alpha-\phi$ \\
Workers in suburb & $(1+\beta) \ln \left(p a_{S}\right)-\beta \ln p$ \\
Bobos in city & $(1+\beta) \ln \left(a_{1}-R\right)-\beta \ln p^{*}+\alpha-\phi$ \\
Bobos in suburb & $(1+\beta) \ln a_{1}-\beta \ln p$ \\
Cadres in city & $(1+\beta) \ln \left(a_{2}-R\right)-\beta \ln p^{*}+\alpha-\phi$ \\
Cadres in suburb & $(1+\beta) \ln a_{2}-\beta \ln p$ \\
\hline \hline
\end{tabular}

Table 2: Utilities

\subsection{Locational decisions}

Given those assumptions, a number of configurations may arise regarding the city's sociological composition. I am only going to consider equilibria that satisfy the following characteristics:

1. It is never optimal for cadres to work in the city.

Clearly, this will hold provided $b$, the land intensity of the old economy technology, is large enough.

2. Workers are at their reservation utility $\bar{u}$.

For this to hold, it is enough that the supply of workers is large enough.

3. All workers cannot be located in the city.

4. Some city residents are not workers.

Finally, I also ignore equilibria where more than one group is located in both areas: that is, groups can be strictly ranked by their marginal willingness to pay to live in the city.

This leaves four possible regimes:

I. All Cadres are in the city (and therefore are a majority), bobos are indifferent between the city and the periphery, and workers live in the suburb

II. All Bobos are in the city, cadres are indifferent between the city and the periphery, and workers all live in the suburb. 
III. All Bobos are in the city, workers live in the city and periphery, cadres are all in the suburb.

IV. All Cadres are in the city, workers are in both locations, and bobos are all in the suburb.

I will first discuss regimes I and II and the transition between the two regimes. Then I will study the specific characteristics of regime III. The analysis of regime IV is left out, because it is less plausible and less relevant to this paper's focus. In particular, as long as bobos are rich enough compared to service workers, they are likely to be willing to pay more to live in the city, and any equilibrium with some workers living in the city must then be such that all bobos live there, implying the economy must be in regime III. ${ }^{16}$

In equilibrium, at least some of the workers residing in the suburb (a nonempty set by assumption 3 above) must sell their services locally. Otherwise, suburban residents would purchase services from city residents, and vice-versa, implying that there would be commuting both ways by workers, which is impossible ${ }^{17}$. This pins down the price of services in the periphery, which must be such that a worker living and working in the suburb gets a utility level equal to $\bar{u}$. From Table 2, column 2, line 2, this yields:

$$
\ln p=\bar{u}-(1+\beta) \ln a_{S}
$$

In both regime I and regime II, all workers live in the suburb. Part of them commute to offer their services to the city ${ }^{18}$. Workers must be indifferent between that option and that of working in the suburb. Consequently, this pins down the price of services in the city:

$$
\begin{aligned}
\ln p^{*} & =\ln p+\frac{\phi}{1+\beta} \\
& =\bar{u}-(1+\beta) \ln a_{S}+\frac{\phi}{1+\beta} .
\end{aligned}
$$

We also need, in those regimes, that workers be below their reservation utility should they decide to live in the city, i.e.

$$
(1+\beta) \ln \left(p^{*} a_{S}-R\right)-\beta \ln p^{*}+\alpha \leq \bar{u} .
$$

\footnotetext{
${ }^{16}$ On the other hand, Cadres may be willing to pay less than service workers to live in the city if commuting costs are very high, as is the case in Regime III.

17 The formulas in Table 2 imply that one would simultaneously have $p>p^{*}$ and $p^{*}>p$.

${ }^{18}$ Otherwise, consumption of services in the city would be zero, implying that their marginal utility there would be infinite. Then, so would be their price, which would make it worth for workers to commute to the city.
} 
Finally, in both regimes, cadres are better-off working in the suburb than in the city. For those living in the suburb (which only happens in regime II), this is clearly always the case, since their net wage is lower in the city due to the cost of land. For those living in the city, from Table 2, row 5 , columns 1 and 2, we get that the folllowing has to hold:

$$
(1+\beta) \ln \left(a_{2}-R\left(1+a_{2} b\right)\right) \leq(1+\beta) \ln \left(a_{2}-R\right)-\phi .
$$

\section{Equilibrium in Regime I}

In Regime I, bobos are indifferent between living in the city and living in the suburb. In either case, they do not pay the commuting cost. Therefore, from Table 2, the following condition must hold:

$$
(1+\beta) \ln \left(a_{1}-R\right)-\beta \ln p^{*}+\alpha=(1+\beta) \ln a_{1}-\beta \ln p
$$

Using (4), we find that this can be reexpressed as

$$
(1+\beta)\left[\ln \left(a_{1}-R\right)-\ln a_{1}\right]=-\alpha+\frac{\beta \phi}{1+\beta} .
$$

This determines the rental cost of housing in equilibrium:

$$
R=a_{1}(1-\exp \lambda(\alpha, \phi))=R_{A}
$$

where subscript $A$ refers to regime I and the $\lambda()$ function is defined by

$$
\lambda(\alpha, \phi)=\frac{\beta \phi-\alpha(1+\beta)}{(1+\beta)^{2}} .
$$

The $\lambda()$ function captures the net utility cost of living in the city for the bobos, ignoring housing. For this regime to be possible, we need that $\lambda \leq 0$ (otherwise from (7) one would have $R<0)$, i.e.

$$
\alpha \geq \frac{\beta \phi}{1+\beta} .
$$

As implied by (7) and (8), house prices are larger, the greater the amenity level and the smaller the commuting cost. The bobos in the city, while not suffering directly from commuting costs, suffer indirectly due to more expensive services in the city. Therefore, the greater the commuting cost, the lower should rents be in the city. Also, housing costs are higher, the greater the bobo's productivity $a_{1}$. This captures the effect of income on the willingness to pay for amenities of the bobos, which is reflected in rental costs, since they are the marginal group of city residents. 
We now turn to the cadres. Their utility is $(1+\beta) \ln \left(a_{2}-R\right)-\beta \ln p^{*}+\alpha-\phi$ (Table 2 , column 2 , line 5). They set amenities so as to maximize this. Recall that $R$ is predetermined when people vote over amenities. Therefore the cadres set amenities by just maximizing $\alpha-\phi(\alpha)-\beta \ln p^{*}$, or equivalently, given (4), $\alpha-\frac{1+2 \beta}{1+\beta} \phi(\alpha)$. Let $\alpha_{A}, \phi_{A}$ be the unique corresponding amenity level and commuting cost. Note that given our assumptions on $\phi$, it must be that $\alpha_{A}-\frac{1+2 \beta}{1+\beta} \phi_{A}>$ 0 , implying in particular that (9) holds. The corresponding utility of the cadres is equal to $(1+\beta) \ln \left(a_{2}-R\right)-\beta \ln p^{*}+\alpha_{A}-\phi_{A}$. For regime I to prevail, this must be weakly larger than their utility from residing in the suburb, which, from Table 2 , column 2 , line 6 , is equal to $(1+\beta) \ln a_{2}-\beta \ln p$. This is equivalent to

$$
\frac{a_{2}}{a_{1}} \geq \frac{1-\exp \left(\lambda_{A}\right)}{1-\exp \left(\mu_{A}\right)}=z_{A}>1
$$

where

$$
\begin{aligned}
\lambda_{A} & =\lambda\left(\alpha_{A}, \phi_{A}\right), \\
\mu_{A} & =\mu\left(\alpha_{A}, \phi_{A}\right)>\lambda_{A},
\end{aligned}
$$

where, by definition

$$
\mu(\alpha, \phi)=\frac{(1+2 \beta) \phi-\alpha(1+\beta)}{(1+\beta)^{2}} .
$$

We note that $a_{2}\left(1-\exp \left(\mu_{A}\right)\right)$ is the cadre's willingness to pay for living in the city. The $\mu()$ function captures the net utility cost of residing in the city for the cadres, ignoring housing costs. Since the cadres, unlike the bobos, have to commute, we have that $\mu(\alpha, \phi)>\lambda(\alpha, \phi)$ for all $\alpha, \phi$. Equation (10) therefore states that in regime I, the cadre's willingness to pay for living in the city is larger than the cost of housing, itself equal to the bobos' - i.e. the marginal group's - willingness to pay for living in the city.

The preceding discussion derives necessary conditions for an equilibrium in regime I to exist. From there, it is easy to establish necessary and sufficient conditions, as stated in the following Proposition.

Proposition 1 - A necessary and sufficient condition for an equilibrium in regime 1 to exist is

$$
\max \left(\frac{e^{\bar{u}}}{a_{S}^{\beta}}\left(e^{\frac{\phi_{A}}{1+\beta}}-e^{\lambda_{A}}\right), \frac{a_{2}\left(e^{\frac{\phi_{A}}{1+\beta}}-1\right)}{\left(1+a_{2} b\right) e^{\frac{\phi_{A}}{1+\beta}}-1}\right) \leq R_{A}=a_{1}\left(1-e^{\lambda_{A}}\right) \leq a_{2}\left(1-e^{\mu_{A}}\right) .
$$

Proof - The second part of the inequality is the same as (10), which we have proved is necessary. Substituting the equilibrium values of $p^{*}$ and $R$, given by (4) and (7), respectively, into (5), and 
rearranging, we find that we must have that $R_{A} \geq \frac{e^{\bar{u}}}{a_{S}^{\beta}}\left(e^{\frac{\phi_{A}}{1+\beta}}-e^{\lambda_{A}}\right)$. Performing similar steps with condition (6) yields that $R_{A} \geq \frac{a_{2}\left(e^{\frac{\phi_{A}}{1+\beta}}-1\right)}{\left(1+a_{2} b\right) e^{\frac{\phi_{A}}{1+\beta}}-1}$. Hence the first part of (11) must hold. This proves necessity. Next, assume (11) holds. We already know that the prices defined by (3), (4) and (7) are equilibrium prices for services and housing, conditional on the locational allocation in regime $\mathrm{I}$. We also know that $\alpha_{C}$ is the equilibrium amenity level chosen by the political majority in the city, i.e. the cadres. To prove that the locational choices are equilibrium ones, we just have to prove that under the assumed equilibrium prices and amenity choice, nobody is strictly better-off by picking another location for either work or residence. By construction, (7) holds, implying that the bobos are indifferent; also by construction, (5) holds, implying that the workers are not better-off in the city. Furthermore, since (10) holds, cadres are not better-off in the suburb. This proves that nobody can gain by chosing another residential location. As for work, the only relevant group is the cadres, who may potientally be better-off working in the city. But, by construction, (6) holds, so this is not the case. Hence, all conditions for locational equilibrium are satisfied. QED.

For an equilibrium in regime I to exist, productivity in the new economy must neither be too large nor too small. If it is to small, workers will be willing to pay more than bobos to reside in the city. If it is too large, all bobos will live in the city, leading to a regime II equilibrium.

It is also possible to compute the employment level in the service sector in each location (see Appendix I). We can then check that an increase in the productivity of the new economy has an ambiguous effect on employment in the service sector. On the one hand, such an increase raises aggregate income in the city and the periphery, which has a positive effect on the demand for services. On the other hand, since the bobos are marginal city dwellers, house prices go up, which reduces the demand for services ${ }^{19}$.

These derivations allow us to summarize the main properties of Regime I:

- An equilibrium in regime I prevails if $\frac{a_{2}}{a_{1}}$ is larger than a critical threshold, which is itself greater than 1. Other things equal, bobos are willing to pay more to live in the city than cadres, because the former do not have to commute. Therefore, for cadres to dominate in the city, their income must be larger than that of the bobos by a sufficient margin.

- In regime I, the cost of housing goes up with productivity in the new economy sector.

\footnotetext{
${ }^{19}$ This is related to our assumption that landowners do not reside in the city nor in the periphery. The greater the proportion of landowners who live in the city+periphery system, the lower the negative effect of the increase in house prices on total service demand. Intuitively, if all landowners reside in the city and if they have the same preferences as the other groups, the rise in house prices should not affect total service demand, so that an increase in $a_{1}$ should then have a positive net total effect on service employment.
} 
- In regime I, total employment of unskilled workers may go up or down with productivity in the new economy.

\section{Regime II}

Let us now turn to Regime II. The indifferent social group in residential choice is now the cadres, while the bobos are politically pivotal. The indifference condition for the cadres reads

$$
(1+\beta) \ln \left(a_{2}-R\right)-\beta \ln p^{*}+\alpha-\phi=(1+\beta) \ln a_{2}-\beta \ln p
$$

Using (4) again to reexpress (12), and using subscript $B$ to denote equilibrium values in regime II, we find that house rental costs are now equal to

$$
R=a_{2}(1-\exp \mu(\alpha, \phi))=R_{B}
$$

For this regime to be possible, we need that $\mu \leq 0$, i.e.

$$
\alpha \geq \frac{1+2 \beta}{1+\beta} \phi .
$$

The utility of the bobos is, from Table 2 , column 1 , line 3 , equal to $(1+\beta) \ln \left(a_{1}-R\right)-\beta \ln p^{*}+$ $\alpha$. Therefore, when old, they vote on the amenity level in the city by maximizing $-\beta \ln p^{*}+\alpha$, or equivalently, given (4), $\alpha-\beta \phi(\alpha) /(1+\beta)$. Let $\alpha_{B}, \phi_{B}$ be the corresponding amenity level and commuting cost. The corresponding utility of the bobos is equal to $(1+\beta) \ln \left(a_{1}-R\right)-\beta \ln p^{*}+$ $\alpha_{B}$. For regime II to prevail, this must be larger than their utility from residing in the suburb, which is equal to $(1+\beta) \ln a_{1}-\beta \ln p$. This is equivalent to

$$
\frac{a_{2}}{a_{1}}<\frac{1-\exp \left(\lambda_{B}\right)}{1-\exp \left(\mu_{B}\right)}=z_{B}>1,
$$

where ${ }^{20}$

$$
\begin{aligned}
\lambda_{B} & =\lambda\left(\alpha_{B}, \phi_{B}\right), \\
\mu_{B} & =\mu\left(\alpha_{B}, \phi_{B}\right)>\lambda_{B} .
\end{aligned}
$$

Again, we can establish necessary and sufficient conditions for an equilibrium is regime 2 to exist:

\footnotetext{
${ }^{20}$ Again, this inequality means that the bobo's WTP, $a_{1}\left(1-\exp \left(\lambda_{B}\right)\right)$, exceeds the cost of housing, $a_{2}\left(1-\exp \left(\mu_{B}\right)\right)$.
} 
Proposition 2 -A necessary and sufficient condition for an equilibrium in regime 2 to exist is

$$
\max \left(\frac{e^{\bar{u}}}{a_{S}^{\beta}}\left(e^{\frac{\phi_{B}}{1+\beta}}-e^{\lambda_{B}}\right), \frac{a_{2}\left(e^{\frac{\phi_{B}}{1+\beta}}-1\right)}{\left(1+a_{2} b\right) e^{\frac{\phi_{B}}{1+\beta}}-1}\right) \leq R_{B}=a_{2}\left(1-e^{\mu_{B}}\right) \leq a_{1}\left(1-e^{\lambda_{B}}\right) .
$$

Proof - The steps are the same as for the proof of Proposition $1 .{ }^{21}$

Finally, we can show that equilibria in the two regimes coexist for some parameter range.

Proposition $3-(i) z_{B}>z_{A}$

(ii) Let $f=\max \left(\frac{\frac{\phi_{B}}{e^{1+\beta}}-e^{\lambda_{B}}}{1-e^{\lambda_{B}}}, \frac{\frac{\phi_{A}}{e^{1+\beta}}-e^{\lambda_{A}}}{1-e^{\lambda_{A}}}\right)$ and $g=\max \left(e^{\mu_{B}}\left(1-e^{-\frac{\phi_{B}}{1+\beta}}\right),\left(\frac{1-e^{\lambda_{B}}}{1-e^{\lambda_{A}}}+e^{\mu_{B}}-1\right)(1-\right.$ $\left.\left.e^{-\frac{\phi_{A}}{1+\beta}}\right)\right)$. Assume that

$$
a_{2} \geq \max \left(z_{B} \frac{e^{\bar{u}}}{a_{S}^{\beta}} f, \frac{g}{b\left(1-e^{\mu_{B}}\right)}\right) .
$$

Then for

$$
\frac{a_{2}}{z_{B}} \leq a_{1} \leq \frac{a_{2}}{z_{A}},
$$

there exists equilibria in both regimes.

Proof - Observe that $\phi_{B}>\phi_{A}$ and $\alpha_{B}>\alpha_{A}$. Furthermore, $\alpha_{B}=\arg \max -\lambda(\alpha, \phi(\alpha))$ and $\alpha_{A}=\arg \max -\mu(\alpha, \phi(\alpha))$. Therefore, $\lambda_{A}>\lambda_{B}$ and $\mu_{B}>\mu_{A}$. From there, (i) follows from the definitions of $z_{A}$ and $z_{B}$ in (10) and (15). To prove (ii), assume (17) and (18) holds. Then, clearly, so do (16) and (11) ${ }^{22}$. Therefore, an equilibrium in each regime exists. QED.

Proposition 3 implies that if (17) holds, then there exists a nonempty range of values for $a_{1}$ where an equilibrium in regime I coexists with an equilibrium in regime II. Expecting to win the election makes it more valuable for the winning group to locate in the city, as they get an

${ }^{21}$ Observe that if (16) holds, then (14) necessarily holds. First, note that from (8) and the fact that $\alpha_{B}=\arg \max$ $\alpha-\beta \phi(\alpha) /(1+\beta), \lambda_{B} \leq 0$. Then from the first part of (16), $\mu_{B}<0$, since $e^{\frac{\phi_{B}}{1+\beta}}-e^{\lambda_{B}}>0$. In other words, rents must be strictly positive for workers not to want to reside in the city.

${ }^{22}$ For example, rearranging the inequality $\frac{a_{2}\left(e^{\frac{\phi_{B}}{1+\beta}}-1\right)}{\left(1+a_{2} b\right) e^{\frac{\phi_{B}}{1+\beta}}-1} \leq a_{2}\left(1-e^{\mu_{B}}\right)$ in $(16)$ yields $e^{\frac{\phi_{B}}{1+\beta}}-1 \leq\left(1-e^{\mu_{B}}\right)((1+$ $\left.\left.a_{2} b\right) e^{\frac{\phi_{B}}{1+\beta}}-1\right)$, or equivalently

$$
\begin{aligned}
a_{2} & \geq \frac{1}{b}\left(e^{\frac{\phi_{B}}{1+\beta}}-1\right) e^{\mu_{B}} \frac{e^{-\frac{\phi_{B}}{1+\beta}}}{1-e^{\mu_{B}}} \\
& =\frac{e^{\mu_{B}}\left(1-e^{-\frac{\phi_{B}}{1+\beta}}\right)}{b\left(1-e^{\mu_{B}}\right)}
\end{aligned}
$$


amenity level more aligned with their preferences. Therefore, that expectation is to some extent self-fulfilling ${ }^{23}$. Note that condition (17) will always hold for $b$ large enough and $\bar{u}$ low enough.

Finally, we can again compute unskilled employment in both locations in regime II. In this regime, house prices are independent of productivity in the new economy. Consequently, productivity in the new economy has a positive effect on service employment because there is no offsetting force coming from the increase in house prices. In the city, the demand for services goes up due to the enhanced income of the bobos. In the periphery, it also goes up because of the positive spillovers on income in the periphery of the additional service workers hired by the bobos in the city.

\section{Comparing regime II with regime I}

I now establish a number of results regarding the comparison between the two regimes ${ }^{24}$.

Proposition 4-Amenities, and therefore commuting costs and the price of services in the city, are larger in regime II.

This result is straightforward: As the bobos do not have to commute, they incur a lower cost from increasing amenities. Therefore they vote for a greater amenity level.

Proposition 5 - House prices are larger in regime II if and only if

$$
\frac{a_{2}}{a_{1}}>\frac{1-e^{\lambda_{A}}}{1-e^{\mu_{B}}}=\tilde{z} \in\left[z_{A}, z_{B}\right]
$$

House prices may go up as the bobos take over, because amenities make living in the city more desirable. But, at the same time, the cadres become the marginal buyers of land and they suffer from the excess level of amenities and transportation costs. The political takeover of the bobos which holds from (17). Similarly, in (11), the inequality $\left.\frac{a_{2}\left(e^{\frac{\phi_{A}}{1+\beta}}-1\right)}{\left(1+a_{2} b\right) e^{\frac{\phi_{A}}{1+\beta}}-1}\right) \leq a_{1}\left(1-e^{\lambda_{A}}\right)$ is satisfied for $a_{1} \geq a_{2} / z_{b}$ provided $\frac{e^{\frac{\phi_{A}}{1+\beta}}-1}{\left(1+a_{2} b\right) e^{\frac{\phi_{A}}{1+\beta}}-1} \leq \frac{1-e^{\lambda_{A}}}{z_{B}}$, and this inequality is equivalent to

$$
a_{2} \geq \frac{\left(1-e^{-\frac{\phi_{A}}{1+\beta}}\right)}{b}\left[\frac{\left(1-e^{\lambda_{B}}\right)}{\left(1-e^{\lambda_{A}}\right)\left(1-e^{\mu_{B}}\right)}-1\right]
$$

which also holds from (17). The other conditions can be checked immediately.

${ }^{23}$ This multiplicity issue is recognized in Epple et al. (1984) and Westhoff (1977).

${ }^{24}$ All proofs are in the Appendix. 
would increase house prices if the cadres are rich enough compared to the bobos at the time of a transition from regime I to regime II.

The model does not systematically validate the naive view that more amenities would increase house prices, since in regime II the marginal city dwellers suffer from greater commuting costs, that are the price to be paid for raising the amenity level. This prediction stands in contrast to what would be expected from a central business district model where all economic activity takes place in the city.

We can also compare the employment levels of unskilled workers in the two regimes. The preceding analysis highlights three effects:

- The price of services is higher in the city in the regime where the bobos are politically decisive. This tends to reduce the demand for services and unskilled employment. Essentially, greater commuting costs are similar to a negative productivity shock affecting the service sector.

- If the cost of housing $(R)$ is larger in regime II than in regime I, this depresses the demand for services in the city. The converse holds if the cost of housing actually falls in regime II compared to regime I.

- In regime II, the bobos who live in the suburbs are replaced by cadres. In the zone where a switch may occur, the latter are richer than the former. The cadres who live in the suburb instead of the city consume more services than the bobos they have replaced. The bobos who live in the city instead of the suburb consume fewer services than the cadres they have replaced. But, because services are more expensive in the city, the former effect is stronger than the latter. On net, therefore, this change in the suburban bourgeois population tends to raise service employment.

Despite those ambiguities, we can get a sufficient condition for service employment to be lower in regime II than in regime I:

\section{Proposition 6-Assume that}

$$
\phi_{A}<-(1+\beta) \ln (1-\beta) .
$$

and

$$
R_{B}>R_{A}
$$


Then at the margin of a transition from regime I to regime II,

$$
L_{P}^{B}+L_{C}^{B}<L_{P}^{A}+L_{C}^{A}
$$

Therefore, if a transition from regime I to regime II is associated with higher housing costs and if the initial amenity level picked by the cadres in the city is low enough, such a transition is harmful for the employment of uskilled service workers.

\section{The bunkerized equilibrium (regime III)}

In this section I characterize an equilibrium in regime III, where only workers and bobos live in the city, the latter being all located there and therefore being a political majority, and cadres are all in the suburb. Such a regime is likely to exist, for the following reason: if workers are initially located in the city, and are numerous enough to be the sole providers of services in that community, then, contrary to regimes I and II, an increase in commuting costs no longer raises the price of services in the city. This will induce city residents to elect the highest possible level of amenities, making it very costly for the cadres to locate in the city ex-ante and commute to work ${ }^{25}$. In such a regime, the city becomes bunkerized, in that no commuting takes place between the city and the periphery.

Let us now characterize this regime. I will limit the analysis to the zone where a regime II equilibrium also exists, i.e. I assume that (16) holds..

\subsection{Equilibrium determination and properties}

First, it must be that workers are indifferent between locating in the city and the periphery. We assume (and will check that it holds in equilibrium), that workers do not commute. Therefore, we have from Table 2, column 1, line 1 and column 2, line 2, that

$$
\begin{aligned}
\bar{u} & =(1+\beta) \ln \left(p^{*} a_{S}-R\right)-\beta \ln p^{*}+\alpha \\
& =(1+\beta) \ln \left(p a_{S}\right)-\beta \ln p .
\end{aligned}
$$

Hence, the price of services in the suburbs is still determined by (3). However, the price of services in the city is determined by a local equilibrium between supply and demand. Total city income, denoting by subscript $C$ equilibrium values in regime III, is given by

$$
Y_{C}=a_{1} H_{1}+p^{*} a_{S}\left(X-H_{1}\right)-X R .
$$

\footnotetext{
${ }^{25}$ One also has to check that working in the city delivers too low a wage for the cadres, as captured by Proposition 7 , condition iv.
} 
Equilibrium in the service market in the city is such that

$$
L_{C}=\frac{\beta}{1+\beta} \frac{Y_{C}}{p^{*} a_{S}}=X-H_{1} .
$$

Eliminating $Y_{C}$ between these two equations and rearranging, we get that

$$
R=a_{1} \frac{H_{1}}{X}-\frac{a_{S}}{\beta} p^{*}\left(1-\frac{H_{1}}{X}\right) .
$$

This defines a downward sloping relationship between $R$ and $p^{*}$, labeled SME. The greater the cost of housing, the lower the city dwellers' purchasing power, and the lower the equilibrium price of services.

It can be checked that Equation (19) defines a positive relationship between $p^{*}$ and $R$, representing equilibrium in the housing market (HME). The greater $p^{*}$, the greater the incentives for workers to locate in the city, and the higher the equilibrium rental cost of housing. Hence, the two relationships HME and SME uniquely determine the equilibrium values of $R$ and $p^{*}, R_{C}$ and $p_{C}^{*}$.

An increase in the productivity of the new economy shifts SME up and leads to an increase in the price of services and in the cost of housing; part of the rise in the bobos' purchasing power is spent on services, which raises their price and attracts new workers to the city. These workers bid the price of housing up, to the point where they are again indifferent between locating in the city and in the periphery. Note that this response stands in contrast to that of regime II, where the price of services was insulated from the bobo's income due to commuting of workers from the suburbs, and the price of housing also did not depend on the bobo's income because it was pinned down by productivity in the old economy, due to the cadres being the marginal city dwellers.

Furthermore, in the bunkerized regime an increase in $a_{1}$ has no effect on service employment, contrary to regimes I and II. Service employment in the city is constrained by available space (there are $X-H_{1}$ housing units left for the workers), and service employment in the suburb is determined by the cadre's income, which is independent of $a_{1}$.

An increase in the amenity level $\alpha$ shifts HME up: workers have a greater incentive to locate to the city, which bids rents up, eventually depressing the demand for, and prices of services.

Note that $\alpha$ does not affect $p^{*}$, since the supply of services is frozen by the locational decisions of service workers, which takes place before voting over $\alpha$. Therefore, the bobos will simply maximize $\alpha$ and pick the highest possible level of amenities $\alpha_{C}$, so that $\phi=\phi_{C}{ }^{26}$

\footnotetext{
${ }^{26}$ As discussed in footnote 27, for high values of $a_{1}$ regime III is replaced by regime IIIB where not all bobos live in the city, and where workers may even be a political majority. Since the workers do not commute, in such a regime they will choose the same (maximum) level of $\alpha$ as in regime III.
} 
Proposition 7 in Appendix I provides precise necessary and sufficient conditions for a regime III equilibrium to exist. I now discuss its properties using a numerical example.

\subsection{A numerical example}

Given that we cannot get a closed form solution for $p^{*}$ and $R$, I compute a numerical solution for the bunkerized equilibrium, checking that all the conditions in Proposition 7 hold. The key variables of interest are reported in Figures 1-3, as a function of $a_{1}$. The range of values for $a_{1}$ is such that equilibria in both regimes II and regime III exist - below this range, an equilibrium in regime II does not exist since (16) is violated, and above this range, the simulations indicate that condition (ii) above is violated, meaning that house and service prices become so high that bobos prefer to live in the periphery ${ }^{27}$. The parameter values corresponding to those figures are $X=1, H_{1}=H_{2}=0.7, \bar{u}=-2, a_{S}=1, a_{2}=1.5, \beta=1, \phi(\alpha)=\alpha^{4}, b \geq 0.11$, and I impose a maximum value of $\alpha, \alpha_{C}=5$ (which will hence prevail in regime III, along with a very high transportation cost $\phi=625){ }^{28}$

Figure 1 plots the rental cost of housing as a function of $a_{1}$, while Figure 2 reports the price of services. As a comparison benchmark, their corresponding values for regime II are plotted too. As proved above, both $p^{*}$ and $R$ go up with $a_{1}$. Furthermore, both are well above their regime II counterpart for the whole range of values of $a_{1}$. This is relatively intuitive: the very high level of amenities that is voted for in regime III makes it highly desirable to reside in the city, as long as one does not commute; and services are relatively scarcer in regime III because they cannot be imported from the periphery.

Figure 3 compares the bobo's utility between the two regimes. We see that for relatively low levels of $a_{1}$, the bobos are better-off in the bunkerized equilibrium: despite higher land and

${ }^{27}$ One can check that an equilibrium, labelled Regime IIIB, with two indifferent groups then arises, as not all the bobo population lives in the city. Services prices are so high that the property that bobos are willing to pay more to live in the city than workers no longer holds. Regardless of the mix between workers and bobos in the city, the amenity level will be set at its maximum, since neither bobos nor workers commute.

The conditions that characterize Regime IIIB are briefly discussed in the Appendix.

${ }^{28}$ We can check that $\frac{e^{\bar{u}}}{a_{S}^{\beta}}\left(e^{\frac{\phi_{B}}{1+\beta}}-e^{\lambda_{B}}\right)=0.064$ and that $a_{2}\left(1-e^{\mu_{B}}\right)=0.14$, while the inequality $\left.\frac{a_{2}\left(e^{\frac{\phi_{B}}{1+\beta}}-1\right)}{\left(1+a_{2} b\right) e^{\frac{\phi_{B}}{1+\beta}}-1}\right) \leq$ $a_{2}\left(1-e^{\mu_{B}}\right)$ is equivalent to

$$
b \geq \frac{e^{\mu_{B}}\left(1-e^{-\frac{\phi_{B}}{1+\beta}}\right)}{a_{2}}=0.1087
$$

Therefore, the first part of (16) holds for our set of parameter values, while the second part holds by construction, given the range of values of $a_{1}$ that is considered. 


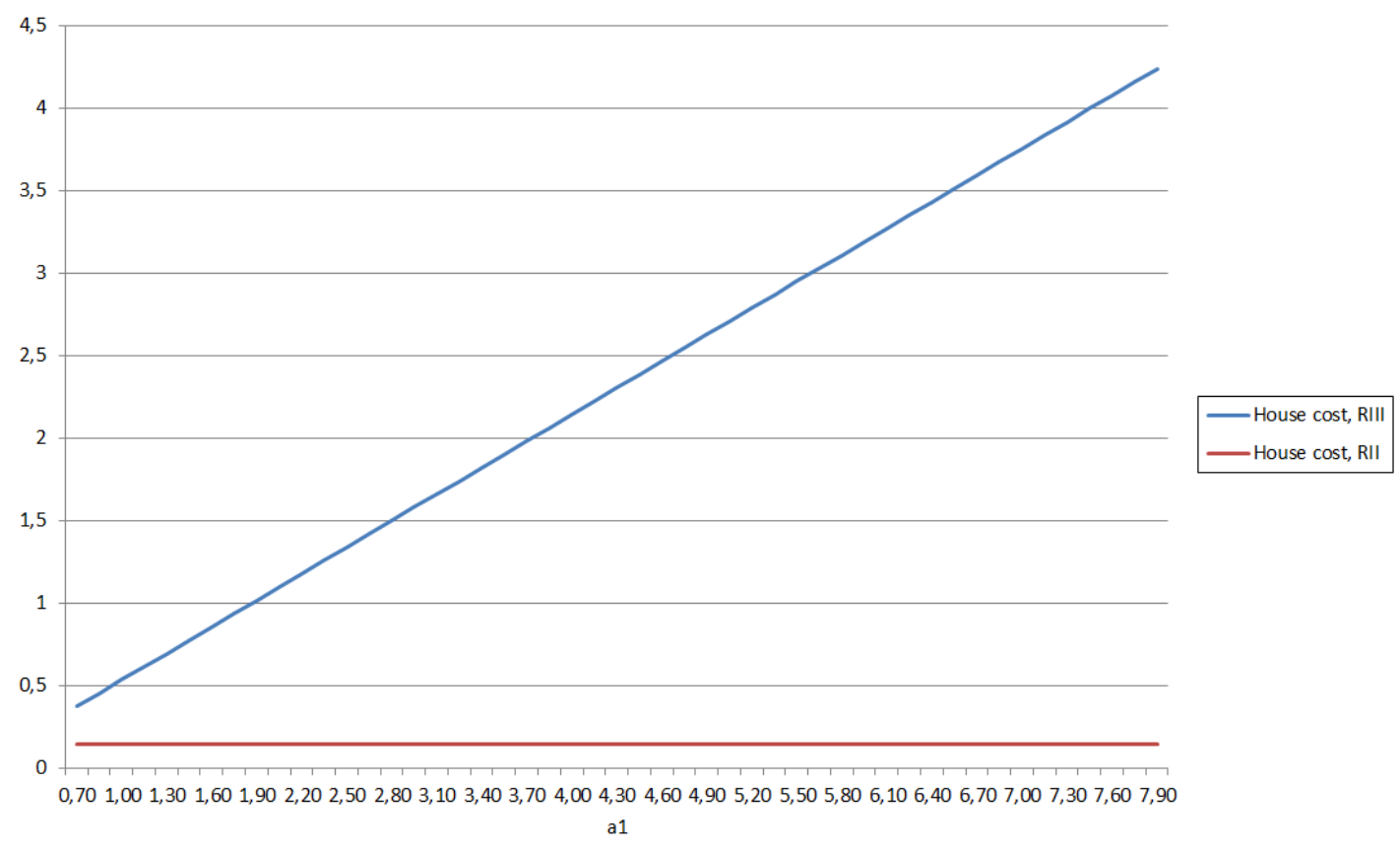

Figure 1: House rental price in regimes II and III

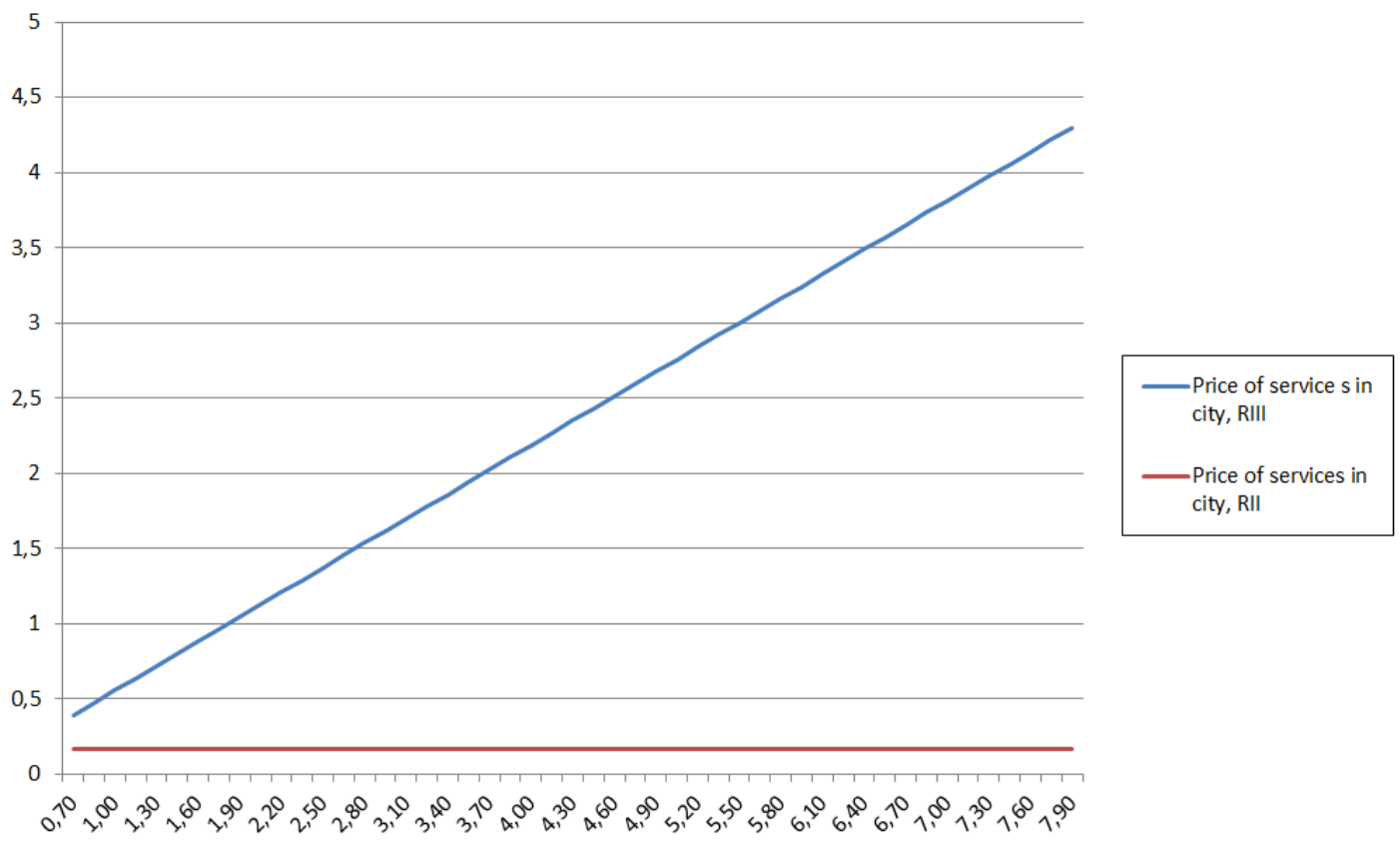

a1

Figure 2: Service price in city in regimes II and III 


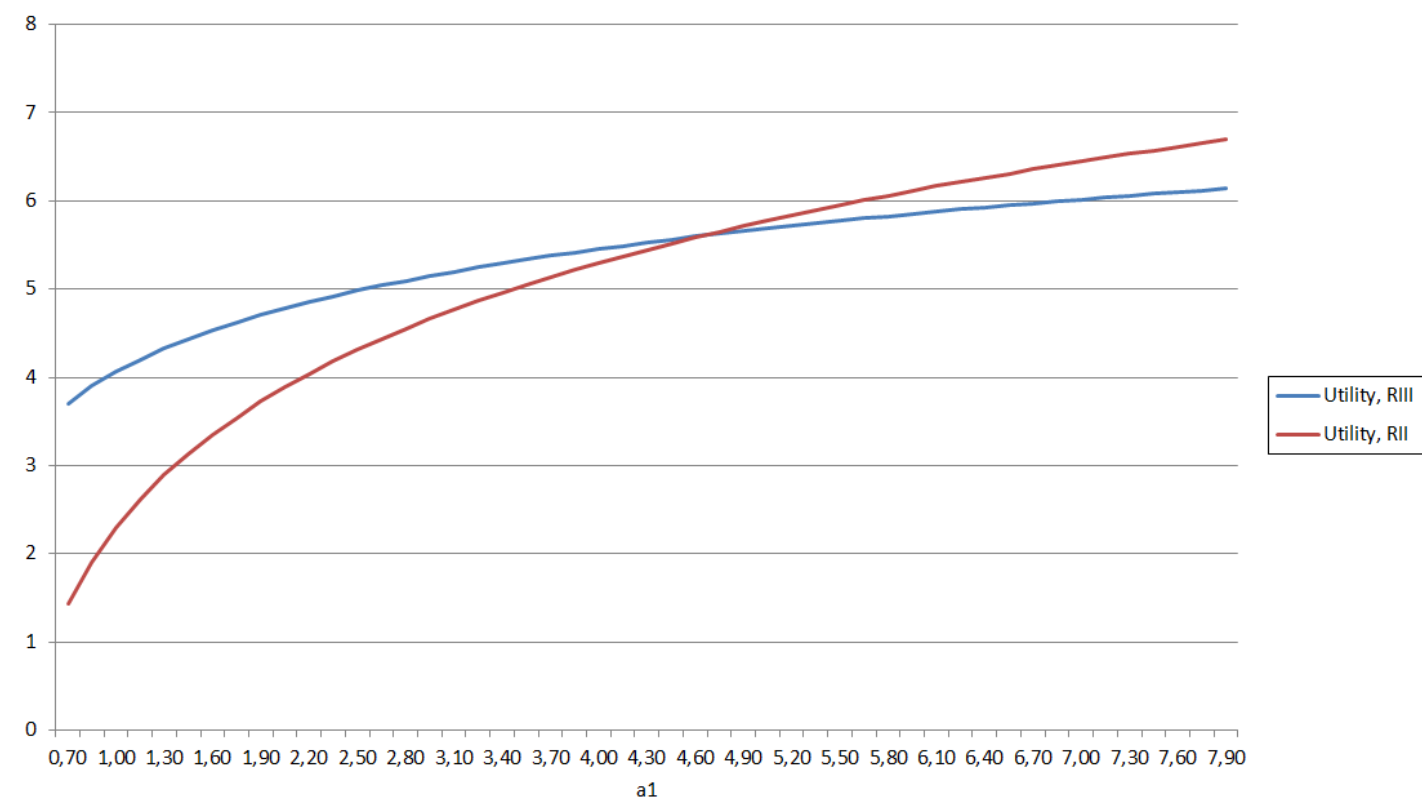

Figure 3: Bobo utility in regimes II and III

service prices, they enjoy a greater amenity level. If $a_{1}$ is high, however, amenities are no longer sufficient to compensate the bobos for the greater prices of services and housing in the bunkerized equilibrium (and for even higher level the bobos are better-off in the periphery and regime III ceases to exist).

\section{8 "Diversity"}

In this section I illustrate how the model may be useful to understand the reason why a city politically dominated by bobos may want to subsidize lower class service workers for residing in the city. Based upon the preceding discussion, we may think of a number of economic mechanisms through which such subsidies may raise the utility of the bobos:

1. If amenities and commuting costs are high, bringing the workers in the city may reduce urban service prices ${ }^{29}$. Intuitively, this effect alone should not be enough to make it rational to subsidize service workers. Absent an externality, taxing oneself to subsidize a good cannot improve welfare.

${ }^{29}$ This is a complementarity in consumption between skilled and unskilled workers; see Bénabou (1993) for an analysis of the role of production complementarities in the urban make-up of a city. 
2. If, contrary to the assumptions made above, the bobos were not numerous enough to capture political power, the presence of non-commuting workers in the city might help them build a coalition in favor of high amenities/high commuting costs.

3. A subsidy for workers to reside in the city may force the equilibrium to be in regime III, that is, it could eliminate an equilibrium in regime II. This may be profitable for the bobos whenever the bunkerized equilibrium delivers a higher utility to them.

4. By triggering a shift from a low amenity to a high amenity equilibrium, such subsidies may raise house prices, thus delivering capital gains to the incumbent city dwellers. This effect is absent by construction in the static model discussed here ${ }^{30}$.

The mechanism described in point 3 can easily be analyzed within the context of the model, provided we assume that there is some way for the bobo caste as a whole to commit over such a tax policy. Let us assume that any working class person is paid a subsidy $s$ to reside in the city, and that this subsidy is financed by a tax $\tau$ levied on the bourgeois. Let us assume that $a_{1}$ is high enough to rule out a regime I equilibrium. For a regime II equilibrium to exist, it must be that in such an equilibrium the working class are not better-off living in the city, i.e. ${ }^{31}$

$$
(1+\beta) \ln \left(p_{B}^{*} a_{S}-R_{B}+s\right)-\beta \ln p_{B}^{*}+\alpha_{B}<\bar{u}
$$

This defines a maximum subsidy level beyond which regime II ceases to exist, which, given (3) and (4), is equal to

$$
s_{\min }=R_{B}-e^{\bar{u}} a_{S}^{-\beta}\left(e^{\frac{\phi}{1+\beta}}-e^{-\frac{\alpha_{B}}{1+\beta}} e^{\frac{\beta \phi}{(1+\beta)^{2}}}\right) .
$$

If $s>s_{\min }$ the economy cannot be in regime II, and a regime III equilibrium is determined by the HME and SME conditions, the former being modified to take the subsidy into account: ${ }^{32}$

$$
(1+\beta) \ln \left(p_{C}^{*} a_{S}+s-R_{C}\right)+\alpha_{C}-\beta \ln p_{C}^{*}=\bar{u} .
$$

Clearly, an increase in $s$ shifts HME up, raising housing costs and reducing service prices. This will harm bobos ${ }^{33}$. However, they may benefit from a subsidy slightly above $s_{\min }$ if it is believed

\footnotetext{
30 The overlapping generations version of the model, described in Appendix III, could provide a basis for incorporating such an effect.

${ }^{31}$ If such an equilibrium exists, it has the same values of $\alpha, R$ and $p^{*}$ as in Section 5, since the tax $\tau$ is equal to zero, as no worker takes advantage of living in the city.

32 The SME condition is unchanged as the transfer from skilled workers to unskilled ones has no effect on the demand for services, given homothetic preferences.

33 Their disposable income falls because of greater taxes and higher house prices. As they spend a constant income share on each good, they must consume less of the generic good. In equilibrium, they consume the same amount of services, while the amenity level is unchanged and equal to its maximum. On net, therefore, their utility must fall.
} 
that the economy would be in regime II absent such a subsidy. For this to be the case it must be that their utility is higher in regime III under $s=s_{\min }$ than in regime II, that is

$$
(1+\beta) \ln \left(a_{1}-R_{C}-\tau_{\min }\right)-\beta \ln p_{C}^{*}+\alpha_{C}>(1+\beta) \ln \left(a_{1}-R_{B}\right)-\beta \ln p_{B}^{*}+\alpha_{B},
$$

where $\tau_{\min }=s_{\min } \frac{X-H_{1}}{H_{1}}$ is the tax rate associated with the minimum subsidy, given the city's budget constraint.

I have checked that condition (22) holds for the parameter values used in the simulations of Section 7.2, for $a_{1} \leq 4.45$. This is only slightly below the value of $a_{1}$ for which the two equilibria yield the same utility to bobos absent a subsidy (see Figure 3), because the subsidy level which eliminates regime II turns out to be relatively small.

The subsidy allows the bobos to change the sociological make-up of the city, which in turn allows them to implement a high level of amenities and commuting costs, while the pool of service workers who are located in the city because of the subsidy prevents service prices from becoming prohibitively high in response to bunkerization. In this multiple equilibrium world, taxing oneself to subside others works because it allows to enforce a more favorable equilibrium.

\section{Evidence from French cities}

In this section I provide some supportive evidence for the model. I use data for 49 of the 50 largest French urban areas ${ }^{34}$, which allow to study the evolution of urban transportation amenities, the sectoral composition of employment, house prices, the fraction of the population in subsidized housing, and the political orientation of the ruling municipal council ${ }^{35}$. I focus on the 2008-2012 period, which follows the 2008 municipal elections.

The preceding analysis shows that investment in urban amenities tends to be larger, the greater the political power of workers in the new economy, i.e. the greater the initial fraction of those workers. Furthermore, bunkerization is associated with positive comovements between amenities, subsidized housing, service employment and house prices; and to the extent that bunkerization is more likely to arise under bobo incumbency, in that regime we also expect to observe a greater than average initial fraction of employment in the new economy. Finally, conventional wisdom suggests that bobo power is associated with a left-wing municipality, although actual outcomes depend on the nature of electoral competition: If platform convergence arises as in Downsian competition, right-wing municipalities will also pursue those policies.

\footnotetext{
34 The city of Annemasse was dropped from the sample, as it is generally considered as part of the Geneva urban area. ${ }^{35}$ See Appendix II for data sources.
} 
In order to test those predictions, I split my sample into three groups, using an aggregate index of transportation amenities. I have data for two types of amenities: tramways ("tram") and public self-service rental bicycles ("vélib"). Both types of investment were explicitly associated with the goal of reducing the scope of car travel in urban areas. For example the Paris tramway is a substitute for a former bus line (the "petite ceinture"), but was built in order to reduce the number of entry points for cars into downtown Paris ${ }^{36}$. Similarly vélibs are associated with a massive conversion of parking space into vélib delivery spots, and of car transit lanes into bicycle lanes. Overall, while these policies introduce more "ecological" means of transportation, it is plausible to assume that they tend to have adverse effects on commuting costs.

I can compute the increase in the number of tramway lines between 2007 and 2012, denoted by $T R A M$; I can also construct a dummy equal to 1 , called $V E L I B$, if the city introduces vélibs between 2007 and 2012. For any given value of $\alpha$, I can construct an aggregate amenity index equal to

$$
A M E N(\alpha)=V E L I B+\alpha T R A M
$$

Groups I,II, and III are then defined as the upper, middle and bottom thirds of the ranking of cities by $A M E N(\alpha) .{ }^{37}$ Although the assignment to each group is exogenous, due to the relatively small number of observations, we could loosely think of group I being in regime III, group II in regime II, and group III in regime I.

Table 3 reports the mean values of the variables of interests, for $\alpha=0.1$. The ranking and results turn out to be quite robust to the choice of $\alpha$, for $\alpha \in[0.1,9]{ }^{38}$

The numbers in Table 3 are overall supportive of the model, although not all differences are statistically significant. Cities that invested more in amenities after the 2008 elections tend to be those with a greater fraction of workers in the new economy, either in the workforce at large or among highly skilled workers, and experienced stronger growth in house prices thereafter. They are also more likely to have raised the fraction of households in social housing ("HLM") and to have

\footnotetext{
${ }^{36}$ See, "Tramway à Paris: Delanoë est-il l'ennemi de la voiture?", L'Express, december 152012 , http://www.lexpress.fr/actualite/politique/tramway-a-paris-delanoe-est-il-1-ennemi-de-la-voiture_1199483.html

${ }^{37}$ Because many cities share the same values for $\operatorname{AMEN}(\alpha)$, however, and because it does not make sense to assign cities with the same value to different groups, the resulting groups turn out to have different sizes. In particular, the bottom group is reduced to all cities for whom $\operatorname{AMEN}(\alpha)$ is equal to zero, while a large set of cities with equal scores equal to the threshold for the top third has to be assigned to group II, otherwise that group would only have three cities. As a result, group I has 11 cities.

A two-group decomposition has also been tried, with similar results.

${ }^{38}$ Only three cities change categories when comparing the assignment for $\alpha=9$ to $\alpha=0.1$ : Brest, Le Mans and Reims which all move from group II to group I.
} 
more service employment, in accordance with the above discussion on bunkerization. However, taken individually, these latter differences are not statistically significant. Finally, a large increase in the amenity level does not seem to be especially related to a left-wing municipality. This is consistent with the Downsian prediction of platform convergence. Indeed, the 2014 campaign of the right-wing contender for the Paris municipality, Nathalie Kosciusko-Morizet, was fully supportive of the policies that are generally associated with the Bobo establishment ${ }^{39}$.

\begin{tabular}{lllll}
\hline \hline Variable & Average group I & Average group II & Average group III & p-value \\
\hline HLM & $0.5(0.4)$ & $-0.2(0.2)$ & $-0.1(0.4)$ & 0.27 \\
Service employment & $0.54(0.1)$ & $0.53(0.06)$ & $0.34(0.15)$ & 0.49 \\
Left & $0.63(0.15)$ & $0.75(0.1)$ & $0.61(0.1)$ & 0.64 \\
New economy & $9.5(0.9)$ & $8.5(0.7)$ & $6.4(0.3)$ & 0.002 \\
NE execs & $50.1(2.1)$ & $48.9(1.7)$ & $44.5(1.3)$ & 0.03 \\
House prices & $3.8(2.6)$ & $1.3(1.9)$ & $-3.0(1.8)$ & 0.09 \\
\hline \hline
\end{tabular}

Table 3: Average values of economic variables by amenity groups. The last column is the p-value for an ANOVA test of equality between those averages. Standard errors in parentheses. HLM = Increase in population share in subsidized housing, 2007-2012, \%. Service employment - Increase in the share of population in services to households, 2007-2012, $\%$. Left - Dummy for left-wing municipality in 2007. New economy - Share of total employment in the new economy, as defined by the following industries: Culture, leisure, conception, research, intellectual services; \%, 2007. NE Execs Share of total employment in the new economy, as defined in the preceding industries, among executives. House prices Increase in area house prices, $\%, 2007-2012$.

\section{Conclusion}

This paper has shown that one can explain some recent trends in urban sociology and policies without referring to an evolution of the preferences of the decisive voters in the city, regarding urban amenities, transportation infrastructure, and housing subsidies for the lower class. Rather, these trends can be explained by productivity growth in the new economy goods relative to other sectors, along with the specificity of the production process for those goods. Of course, as documented by the original book by Brooks, preferences may matter in other dimensions (such as consumption of organic food or specific details of home interior decoration) that are not treated by the model analyzed here. It is possible, though, that these aspects of the new urban elite's lifestyle also are a consequence of their economic characteristics, especially if one allows for endogenous preferences. This is a productive avenue for further research.

\footnotetext{
${ }^{39}$ See "The harpist or the heiress? Image is all in the race to be first woman mayor of Paris", The Guardian, March 2 2014, in which it is stated that "[Nathalie Kosciusko-Morizet] was photographed using a free Vélib' bicycle(...)."
} 


\section{References}

Anas, A., Arnott, R. and Small, K. A. (1998). Urban spatial structure. Journal of Economic Literature, 36(3): 1426-1464. https://www.jstor.org/stable/2564805?seq=1\#page_scan_tab_ contents.

Anas, A. and Kim, I. (1996). General equilibrium models of polycentric urban land use with endogenous congestion and job agglomeration. Journal of Urban Economics, 40(2): 232-256. https://doi.org/10.1006/juec.1996.0031.

Barthes, R. (1957). Mythologies. Paris: Editions du Seuil.

Benabou, R. (1993). Workings of a city: location, education, and production. The Quarterly Journal of Economics, 108(3): 619-652. https://doi.org/10.2307/2118403.

Brooks, D. (2000). Bobos in paradise. NY: Simon and Schuster.

Clerval, A. and Fleury, A.(2009). Politiques urbaines et gentrification, une analyse critique à partir du cas de Paris. L'Espace Politique, 8, 2009-2. https://journals.openedition.org/espacepolitique/ 1314\#quotation.

Epple, D., Filimon, R. and Romer, T. (1983). Housing, voting and moving: equilibrium in a model of local public goods with multiple jurisdiction. In Henderson, J. V. Research in Urban Economics. Greenwich: JAI Press.

Epple, D., Filimon, R. and Romer, T. (1984). Equilibrium among local jurisdictions: toward and integrated treatment of voting and residential choice. Journal of Public Economics, 24(3): 281-308. https://doi.org/10.1016/0047-2727(84)90012-4.

Guerrieri, V., Hartley, D. and Hurst, E. (2010). Endogenous gentrification and housing price dynamics. NBER Working Paper No. 16237. http://www.nber.org/papers/w16237.

Guilluy, C. (2010). Fractures françaises . Paris: François Bourin.

Glass, R. (1964). Introduction: aspects of change. In London: Aspects of change. London: MacGibbon \& Kee.

Jacobs, J. (1961). The death and life of great American cities. New York: Random House. 
LeRoy, S. F. and Sonstelie, J. (1983). Paradise lost and regained: Transportation innovation, income, and residential location. Journal of Urban Economics, 13(1): 67-89. https://doi.org/10. 1016/0094-1190(83)90046-3.

Okamoto, R. (2007). Location choices of firms and workers in an urban model with heterogeneities in skills and preferences. Regional Science and Urban Economics, 37(6): 670-687. https: //econpapers.repec.org/article/eeeregeco/v_3a37_3ay_3a2007_3ai_3a6_3ap_3a670-687.htm.

Richter, D. K. (1982). Weakly democratic regular tax equilibria in a local public goods economy with perfect consumer mobility. Journal of Economic Theory, 27(1): 137-162. https://doi.org/ 10.1016/0022-0531(82)90018-7.

Roback, J. (1982). Wages, rents, and the quality of life. Journal of Political Economy, 90(6): 1257-1278. https://www.jstor.org/stable/1830947?seq=1\#page_scan_tab_contents.

Roger-Petit, B. (2015). Pollution à Paris: pourquoi l'écologie punitive d'Anne Hidalgo est contre-productive. Challenges. https://www.challenges.fr/politique/ pollution-a-paris-pourquoi-1-ecologie-punitive-d-anne-hidalgo-est-contre-productive_30844.

Rosen, S. (1979). Wage-based indexes of urban, quality of life. In Mieszkowski, P. and Straszheim, M. Current issues in urban economics. Johns Hopkins University Press.

Rose-Ackerman, S. (1979). Market models of local government: exit, voting, and the land market. Journal of Urban Economics, 6(3): 319-337. https://doi.org/10.1016/0094-1190(79)90034-2.

Rossi-Hansberg, E., Sarte, P. D. G. and Owens, R. E. (2008). Housing externalities. NBER Working paper No. 14369. https://papers.ssrn.com/sol3/papers.cfm?abstract_id=1276629.

Seegert, N. (2011). Land regulations and the optimal distribution of cities. Working Paper. https://feb.kuleuven.be/drc/Economics/misc/seminars/papers2015/paper_seegert.pdf.

Westhoff, F. (1977). Existence of equilibrium in economies with a local public good. Journal of Economic Theory, 14(1): 84-112. https://doi.org/10.1016/0022-0531(77)90086-2. 


\section{APPENDIX I: Proofs}

Computing employment in services - Assume the economy is in regime I. Total income in the city is

$$
Y_{C}=a_{2} H_{2}+a_{1}\left(X-H_{2}\right)-R_{A} X
$$

Total service demand in the city is therefore equal to

$$
C_{S C}=\beta \frac{a_{2} H_{2}+a_{1}\left(X-H_{2}\right)-R_{A} X}{(1+\beta) p^{*}} .
$$

Therefore, the number of service workers who work in the city (but live in the periphery) is

$$
\begin{aligned}
L_{C} & =\beta \frac{a_{2} H_{2}+a_{1}\left(X-H_{2}\right)-R_{A} X}{(1+\beta) p^{*} a_{S}} \\
& =\beta \frac{a_{2} H_{2}+a_{1}\left(X-H_{2}\right)-R_{A} X}{(1+\beta) p a_{S}} \exp \left(-\frac{\phi_{A}}{1+\beta}\right) \\
& =L_{C}^{A} .
\end{aligned}
$$

In the periphery, the demand for services comes from the working class and the bobos who live there. Their combined income is

$$
Y_{P}=a_{1}\left(H_{1}+H_{2}-X\right)+p^{*} a_{S} L_{C}+p a_{S} L_{P},
$$

where $L_{P}$ denotes the unskilled employment level in the periphery. Again we must have $L_{P}=$ $\frac{\beta}{1+\beta} \frac{Y_{P}}{a_{S} p}$, yielding

$$
\begin{aligned}
L_{P} & =\frac{\beta}{p a_{S}}\left[\frac{\beta}{1+\beta}\left(a_{2} H_{2}+a_{1}\left(X-H_{2}\right)-R_{A} X\right)+a_{1}\left(H_{1}+H_{2}-X\right)\right] \\
& =L_{P}^{A}
\end{aligned}
$$

Gathering terms, and recalling that $\partial R_{A} / \partial a_{1}=1-e^{\lambda_{A}}>0$, we find that the effect of $a_{1}$ on $L_{P}^{A}+L_{C}^{A}, \partial\left(L_{P}^{A}+L_{C}^{A}\right) / \partial a_{1}$, has the same sign as the following expression

$$
E=(1+\beta)\left(H_{1}-X\right)+\left(X-H_{2}\right)\left(\exp \left(-\frac{\phi_{A}}{1+\beta}\right)-1\right)+X(1+\beta) \exp \left(\lambda_{A}\right) \lesseqgtr 0 .
$$

Indeed, for $\phi(\alpha)=k \alpha^{2}, X=3, H_{1}=H_{2}=2, \beta=0.4$, we get $E=-1.7$ if $k=0.1$ and $E=1.78$ if $k=1$. For $k$ low, amenities are high and commuting costs low in equilibrium, and this raises the impact of the new economy's productivity on house prices. Accordingly, the total demand for services falls with $a_{1}$ in such a configuration. 
It is then straightforward to modify the expressions in (23) and (24) to get service employment in regime II:

$$
\begin{aligned}
& L_{C}^{B}=\beta \frac{a_{1} H_{1}+a_{2}\left(X-H_{1}\right)-R_{B} X}{(1+\beta) p a_{S}} \exp \left(-\frac{\phi_{B}}{1+\beta}\right) \\
& L_{P}^{B}=\frac{\beta}{p a_{S}}\left[\frac{\beta}{1+\beta}\left(a_{1} H_{1}+a_{2}\left(X-H_{1}\right)-R_{B} X\right)+a_{2}\left(H_{1}+H_{2}-X\right)\right]
\end{aligned}
$$

Clearly, as $\partial R_{B} / \partial a_{1}=0$, it is obvious that $\partial L_{C}^{B} / \partial a_{1}>0$ and $\partial L_{P}^{B} / \partial a_{1}>0$.

Proof of Proposition 4 - in regime II, the bobos set $\alpha$ and $\phi$ so as to maximize $\alpha-\beta \phi(\alpha) /(1+$ $\beta$ ). In regime I, the cadres maximize $\alpha-\frac{1+2 \beta}{1+\beta} \phi(\alpha)$.

Proof of Proposition 5 - Straightforward from the expression of house prices and the fact that $\mu_{B}>\mu_{A}>\lambda_{A}>\lambda_{B}$

Proof of Proposition 6 - We have that, using the derivations in the preceding sections,

$$
\begin{aligned}
L_{P}^{B}+L_{C}^{B}-\left(L_{P}^{A}+L_{C}^{A}\right) \propto & \left(a_{2}-a_{1}\right)\left(H_{1}+H_{2}-X\right)\left(1-\beta-e^{-\frac{\phi_{A}}{1+\beta}}\right) \\
& +X\left(R_{A}-R_{B}\right)\left(\beta+e^{-\frac{\phi_{A}}{1+\beta}}\right) \\
& +Z_{B}\left(e^{-\frac{\phi_{B}}{1+\beta}}-e^{-\frac{\phi_{A}}{1+\beta}}\right),
\end{aligned}
$$

where

$$
Z_{B}=a_{1} H_{1}+a_{2}\left(X-H_{1}\right)-R_{B} X>0 .
$$

Clearly, $a_{2}>a_{1}$ since both regimes must exist for the transition to occur. Since one also has $\phi_{B}>\phi_{A}$, all terms above are negative under the assumptions of the Proposition. QED.

\section{Conditions for a bunkerized equilibrium to exist}

Proposition 7 - An equilibrium in regime III exists if and only if the following conditions hold:

(i) $(1+\beta) \ln \left(a_{2}-R_{C}\right)-\beta \ln p_{C}^{*}+\alpha_{C}-\phi_{C}<(1+\beta) \ln a_{2}-\beta \ln p$.

(ii) $(1+\beta) \ln \left(a_{1}-R_{C}\right)-\beta \ln p_{C}^{*}+\alpha_{C}>(1+\beta) \ln a_{1}-\beta \ln p$.

(iii) $(1+\beta) \ln \left(p_{C}^{*} a_{S}\right)-\beta \ln p-\phi_{C}<(1+\beta) \ln \left(p a_{S}\right)-\beta \ln p$.

(iv) $(1+\beta) \ln \left(a_{2}-R_{C}\left(1+b a_{2}\right)\right)-\beta \ln p_{C}^{*}+\alpha_{C}<(1+\beta) \ln a_{2}-\beta \ln p$. 
(v) $\alpha_{C}-\alpha_{B} \geq \beta\left(\ln p_{C}^{*}-\ln p-\frac{\phi_{B}}{1+\beta}\right)$.

Proof of Proposition 7 - For an equilibrium in regime III to exist, the the cadres must be better-off in the periphery. This is equivalent to (i). Second, the bobos must be better-off in the city, which is equivalent to (ii). Third, the workers in the periphery should not have an incentive to commute to the city, implying that (iii) must hold. Fourth, the cadres should not be better-off locating and working in the city, i.e. (iv) should hold.

Finally, the bobos should not be better-off by deviating from the equilibrium value of $\alpha$ and picking an ex-post level of amenities that would induce the workers to commute to the city. The price that would induce them to do so is given by the RHS of (4), which we now denote by $p_{A B}^{*}(\phi)^{40}$. If this is lower than the autarky price of services obtained from (19) and (20), then suburban workers commute to the city. This happens iff $p_{A B}^{*}(\phi)<p^{*}$, or equivalently

$$
\phi<(1+\beta)\left(\ln p_{C}^{*}-\ln p\right)=\phi_{\max } .
$$

In the zone where $\phi<\phi_{\max }$, the bobo's utility is given by $(1+\beta) \ln \left(a_{1}-R_{C}\right)-$ $\beta \ln p_{A B}^{*}(\phi)+\alpha .^{41}$ Therefore they maximize $\alpha-\beta \phi(\alpha) /(1+\beta)$, as in regime II, and pick $\alpha=\min \left(\alpha_{B}, \phi^{-1}\left(\phi_{\max }\right)\right)=\alpha^{\prime}$. The bobos will vote for this outcome if and only if it delivers a greater utility than the maximum possible value of $\alpha$, that is $(1+\beta) \ln \left(a_{1}-R_{C}\right)-\beta \ln p_{C}^{*}+\alpha_{C}<$ $(1+\beta) \ln \left(a_{1}-R_{C}\right)-\beta \ln p_{A B}^{*}\left(\phi\left(\alpha^{\prime}\right)\right)+\alpha^{\prime}$, or equivalently, denoting by $\phi^{\prime}=\phi\left(\alpha^{\prime}\right)$,

$$
\alpha_{C}-\alpha^{\prime}<\beta\left(\ln p_{C}^{*}-\ln p-\frac{\phi^{\prime}}{1+\beta}\right) \text {. }
$$

We note that if $\phi^{\prime}=\phi_{\max }$, the RHS is equal to zero. The LHS cannot be negative, as $\alpha_{C}$ is the maximum value of $\alpha$. Therefore, this inequality is violated for $\phi^{\prime}=\phi_{\max }$. It may only hold for $\alpha^{\prime}=\alpha_{B}$, which is equivalent to (v) being violated. If that is the case, then ex-post the bobos would pick an amenity level such that workers commute from the suburbs to the city to offer their services. But we can then check that it cannot be rational for workers to locate to the city ex-ante. The reason is as follows: Service prices and amenity levels are the same as in regime II. But in regime II workers prefer to reside in the suburbs, i.e. would get a utility level lower than $\bar{u}$ should they live in the city. For them to locate in the city, it must therefore be that rents are lower than in regime II, that is, $R<R_{B}$. However, we know that under regime II, cadres are indifferent between the two areas. For them to now strictly prefer the periphery, it must be that $R>R_{B}$, a contradiction. Consequently, it must be that (v) holds for regime III to exist.

\footnotetext{
40 The subscript $A B$ refers to the fact that this relationship between $p^{*}$ and $\phi$ must hold in both regimes I and II.

${ }^{41}$ Choosing an amenity level $\alpha^{\prime} \neq \alpha_{C}$ ex-post has no effect on $R$, since the resale value of the home depends on expected future amenities, while the purchase price of the home depends on expected curren amenities, given by $\alpha_{C}$.
} 
Conversely, if (i)-(v) hold, then clearly, the otucome computed in the preceding section 7.1 satisfies all the equilibrium conditions. QED.

Properties of regime IIIB - In regime IIIB, both workers and bobos are located both in the city and periphery. The difference between regime III is two-fold. First, condition (ii) is replaced by an equality, stating that bobos are equally better-off in the city and in the periphery:

$$
(1+\beta) \ln \left(a_{1}-R_{C}\right)-\beta \ln p_{C}^{*}+\alpha_{C}=(1+\beta) \ln a_{1}-\beta \ln p .
$$

Second, the service market equilibrium condition is replaced by an inequality: the demand for services in the city has to be lower than if all bobos were located in the city, implying that

$$
R \leq a_{1} \frac{H_{1}}{X}-\frac{a_{S}}{\beta} p^{*}\left(1-\frac{H_{1}}{X}\right) .
$$

Consequently, the SME schedule has to be replaced by Equation (27), which is again downward sloping, while the HME schedule is unchanged. Given the equilibrium values of $R$ and $p^{*}$, the number of bobos residing in the city, $\tilde{H}_{1}$, is determined by the city equilibrium in the service market, that is

$$
\tilde{H}_{1}=\frac{R+p^{*} a_{S} / \beta}{a_{1}+p^{*} a_{S} / \beta} X
$$




\section{APPENDIX II - Data sources and group assignment}

The data sources were the websites of professional real estate association, www.meilleursagents.com, for house prices, for social housing, the French ministry of housing and the French statistical institute INSEE, and for all other economic variables, INSEE. The electoral data are from the French Interior ministry. The list of trams and vélibs is available from Wikipedia at

https://fr.wikipedia.org/wiki/Liste_des_syst\%C3\%A8mes_de_v\%C3\%A9los_en_libreservice_en_France

and

https://fr.wikipedia.org/wiki/Liste_des_tramways_de_France. This was checked with independent sources: town hall web sites, press articles, and the following web site:

http://www.transbus.org/dossiers/tramway_service.html

The list of urban areas and their group assignment, for $\alpha=0.1$, with group I being the highest amenity level, is as follows:

Group I: Lyon, Toulouse, Bordeaux, Nice, Strasbourg, Montpellier, Saint-Etienne, Orléans, Angers, Dijon.

Group II: Paris, Marseille, Lille, Nantes, Grenoble, Rennes, Rouen, Avignon, Nancy, Caen, Valenciennes, Le Mans, Reims, Brest, Perpignan, Amiens, Besançon, Pau, La Rochelle

Group III: Toulon, Douai, Lens, Tours, Clermont-Ferrand, Metz, Béthune, Le Havre, Limoges, Bayonne, Dunkerque, Poitiers, Nîmes, Lorient, Annecy, Chambéry, Saint-Nazaire, Troyes 


\section{APPENDIX III: Overlapping generations interpretation of the model}

There are overlapping generations of agents who live for two periods. Each cohort's size is equal to one. People can borrow and lend at the fixed real international interest rate equal to $r$. In the first period of their life, people decide where to locate (city vs. suburb), and they purchase housing, if needed, from the preceding generation, at price $q_{t}$. Lenders do not live in the city and appropriate the net return to housing. In the second period of their life, people vote on the level of amenities in the city, work, sell their home to the next generation, and consume.

Preferences and the structure of production are the same as in the text.

The rental cost of housing in the city for generation $t$ is

$$
R_{t}=(1+r) q_{t}-q_{t+1}
$$

The voting decision is made after urban dwellers have picked their residence and paid the house price $q_{t}$, but before selling back their real estate to the new generation. As long as amenities are not a state variable, $q_{t+1}$ will depend on the amenities set by the next generation. Therefore the amenity level decided by generation $t$ has no effect on $q_{t+1}$, and hence no effect on $R_{t}$. In this model, there are no capital gains associated with investing in greater amenities ${ }^{42}$; for this reason, the equilibrium is essentially the same as that of the static model ${ }^{43}$.

Given the equilibrium rental cost of housing (for example $R=R_{B}$ if the economy is in an equilibrium in regime II), Equation (28) defines house price dynamics. The dynamic model delivers some additional results regarding these dynamics along the transition from one regime to another.

Suppose that, due to the progress of the new economy, $a_{1}$ rises over time, while $a_{2}$ remains constant. We know that at some stage, the composition of the city will change: the economy will shift from regime I to regime II. However, due to multiple equilibria, the date of the transition cannot be predicted. During the period such that $a_{2} / a_{1} \in\left[z_{A}, z_{B}\right]$, multiple transitions in both

\footnotetext{
${ }^{42}$ This feature greatly simplifies the model but some of the richness of the analysis is lost, as capital gains on real estate disappear as a motivation for investing in amenities. Note that reintroducing them would introduce a conflict of interest between tenants and landowners, and results would be highly sensitive to whether the decisive voter is a tenant or an owner. In the model, while it is assumed that people own their home, their utility only depends on the rental cost of housing and the results would be unchanged if they rented instead.

If amenities were a state variable, then the future amenity level would depend positively on the current one, and investing in amenities would increase the price at which the old generation could resell their homes.

Finally, note that in the analysis of diversity policies below, capital gains play a role, since these policies may irreversibly change the equilibrium regime, thus affecting land prices.

${ }^{43}$ While voters rationally internalize the effects of electoral outcomes on the resale value of their house, contrary to the assumptions made in Epple et al. (1984), this feature does not affect the equilibrium, since $q_{t+1}$ is entirely forward-looking.
} 
directions may even occur. To simplify the analysis, let us plausibly assume that there is a unique transition date $T$. Therefore, the economy is in regime I before $T$ and in regime II after.

The rental cost of housing keeps going up until date $T$, and stabilizes thereafter. As for house prices, before date $T$ they evolve according to

$$
q_{t}=\frac{1}{1+r}\left(q_{t+1}+a_{1 t}\left(1-e^{\lambda_{A}}\right)\right),
$$

since $R_{A t}=a_{1 t}\left(1-e^{\lambda_{A}}\right)$. We can show that house prices go up monotonically in the run-up to the bobo's takeover, provided the transition does not occur too late:

\section{Proposition 8 - Assume}

$$
a_{1 T-1}<a_{2} \frac{1-e^{\mu_{B}}}{1-e^{\lambda_{A}}}
$$

then $q_{t}$ is monotonically increasing with time for $t \leq T$, and constant thereafter.

Condition (29) means that house prices are higher after the transition than before, which, given that $a_{1}$ is growing over time, is a weaker condition than for house prices to be higher in regime II than in regime $\mathrm{I}$.

From Proposition 8 we may conclude that growth in the new economy will generate an upward trend in house prices, but that it should stop once the bobo takeover is complete and once they have completed their investments in urban infrastructure. However, as discussed in Section 7, this levelling off of house prices only takes place if the city does not become bunkerized.

Proof of Proposition 8 - Clearly, for $t \geq T$, we have that $q_{t}=R_{B} / r=a_{2}\left(1-e^{\mu_{B}}\right) / r$. Furthermore, $q_{T-1}=\frac{a_{1 T-1}\left(1-e^{\lambda_{A}}\right)}{1+r}+\frac{R_{B}}{r(1+r)}$. This is clearly lower than $R_{B} / r$ if (29) holds. Furthermore, we have that

$$
q_{t+1}-q_{t}=\frac{q_{t+1} r-a_{1 t}\left(1-e^{\lambda_{A}}\right)}{1+r} .
$$

We now show that this quantity is positive. Note that for $t \leq T-2$

$$
\begin{aligned}
r q_{t+1} & =r \sum_{s=t+1}^{T-1} \frac{a_{1 s}\left(1-e^{\lambda_{A}}\right)}{(1+r)^{s-t}}+\frac{R_{B}}{(1+r)^{T-t-1}} \\
& >a_{1 t}\left(1-e^{\lambda_{A}}\right)\left(1-\frac{1}{(1+r)^{T-1-t}}\right)+\frac{a_{1 T-1}\left(1-e^{\lambda_{A}}\right)}{(1+r)^{T-1-t}} \\
& >a_{1 t}\left(1-e^{\lambda_{A}}\right)\left(1-\frac{1}{(1+r)^{T-1-t}}\right)+\frac{a_{1 t}\left(1-e^{\lambda_{A}}\right)}{(1+r)^{T-1-t}} \\
& =a_{1 t}\left(1-e^{\lambda_{A}}\right) .
\end{aligned}
$$

This proves that $q_{t+1}>q_{t}$. QED. 


\section{Economics}

Please note:

You are most sincerely encouraged to participate in the open assessment of this article. You can do so by either recommending the article or by posting your comments.

\section{Please go to:}

http://dx.doi.org/10.5018/economics-ejournal.ja.2018-56

The Editor 